\title{
An Improved Harmony Search Algorithm for solved the Combined Heat and Power Economic Dispatch
}

\author{
Benayed Fatima Zohra ${ }^{1}$, Abdelhakem koridak Lahouari ${ }^{2}$, and Rahli Mostefa ${ }^{1}$ \\ ${ }^{1}$ Departement of Electrical Engineering, University of Science and Technology, USTO, Algeria \\ ${ }^{2}$ Departement of Mechanical Engineering, University of Science and Technology, USTO, Algeria
}

\begin{abstract}
The Harmony Search (HS) algorithm is a population-based meta-heuristic optimization algorithm. This algorithm is inspired by the music improvisation process in which the musician searches for harmony and continues to polish the pitches to obtain a better harmony. Although several variants of the HS algorithm have been proposed, their effectiveness in dealing with diverse problems is still unsatisfactory. The performances of these variants mainly depend on the selection of different parameters of the algorithm. This paper develops an improved harmony search (IHS) algorithm for solving optimization problems. IHS employs a novel method for generating new solution vectors that enhances accuracy and convergence rate of harmony search (HS) algorithm. The IHS algorithm has been successfully applied to various benchmarking and standard engineering optimization problems. The optimal utilization of multiple combined heat and power (CHP) systems is a complicated problem that needs powerful methods to solve. This paper presents an improved harmony search (IHS) algorithm to solve the combined heat and power economic dispatch (CHPED) problem. In this paper the impacts of constant parameters on harmony search algorithm are discussed and a strategy for tuning these parameters is presented. Numerical results reveal that the proposed algorithm can find better solutions when compared to HS and other heuristic or deterministic methods where IHS algorithm is a powerful for will be effective in the problems of CHPED.
\end{abstract}

Keywords: Combined Heat and Power Economic Dispatch; Improved Harmony Search Algorithm; optimization; cogeneration.

\section{Introduction}

Increasing demand in the use of cogeneration systems that simultaneously produce heat and power is quite remarkable. Combined heat and power generation unit with industrial, commercial and residential applications is an efficient energy resource providing environmental advantages over other forms of conventional energy supply. Utilization of cogeneration units besides conventional power generating units and heat-only units to satisfy heat and electricity demands in an economical manner emphasizes on the need to combined heat and power economic dispatch (CHPED). In the pure economic dispatch problem, power demand is only taken and distributed on in-service generating units. In the CHPED problem, heat demand is also considered and mutual interdependency of heat and power production in cogeneration units introduces more complexity in the problem.

In the CHPED problem, it is tried to find economical optimum solution considering the mentioned complexity of the constraints. Indeed, the purpose of the problem is to specify the output of the units to satisfy heat and power demands with minimum fuel cost [1]. Recently, in order to make numerical methods more convenient for solving the CHPED problems, modern optimization techniques [2], [3] have been successfully employed to solve the CHPED problem as a non-smooth optimization problem. A global optimization technique known as the harmony search (HS) is one of these modern techniques [4].

In this paper, we propose a novel approach for solving the CHPED problem using an improved harmony search (IHS) algorithm. The CHPED system based on the conventional power units, cogenerations units and the heats only units. The Systems data containing valve- point effects coefficients of fuel cost equations and B loss coefficients are obtained from Basu [5]. Numerical results obtained with the proposed IHS approach were compared with classical HS method and

Received: May $14^{\text {th }}, 2018$. Accepted: June $30^{\text {th }}, 2019$

DOI: 10.15676/ijeei.2019.11.2.14 
other optimization results reported in literature. The remainder of this paper is organized as follows. Section 2 explains the formulation of the CHPED problem. In Section 3 the classical HS and the proposed IHS are described. Simulation results of IHS are presented and compared with HS and other algorithms in Section 4. Lastly, Section 5 outlines our conclusions.

\section{CHPED problem formulation}

The propose CHPED problem is an optimization problem, but it is consider some types of produce units such as pure heat units, combined power and heat (co-generation) and conventional power units. The co-generation is role to produce heat and power with feasible operation region according to "Figure. 1", where the boundary curve ABCDEF determines the feasible region [2], [8]. Along the boundary there is a trade-off between power generation and heat production from the unit. It can be seen that along the curve $A B$ the unit reaches maximum output power. In contrast, the unit reaches maximum heat production along the curve $\mathrm{CD}$ [9]. Therefore, power generation limits of cogeneration units are the combined functions of the unit heat production and vice versa [4], [6], [7].

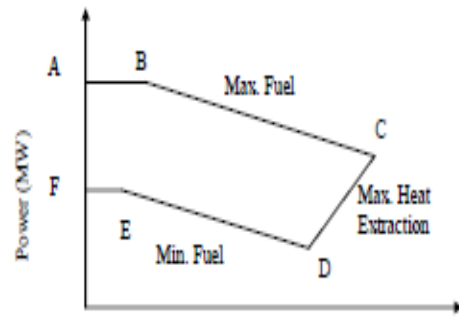

Figureure 1. Typical heat-power feasible region for CHP units

Mathematically, problem is formulated as "(1)" [10]-[11], [12]:

$$
\text { Minimize } F_{\text {fuel }}=\sum_{i=1}^{N_{p}} f_{i}\left(P_{i}\right)+\sum_{j=1}^{N_{c}} f_{j}\left(P_{j}, h_{j}\right)+\sum_{k=1}^{N_{h}} f_{k}\left(h_{k}\right)
$$

Subject to: Power production equilibrium constraint

$$
\sum_{i=1}^{N_{p}} P_{i}+\sum_{j=1}^{N_{c}} P_{j}=P_{D}+P_{L}
$$

Heat production equilibrium constraint

$$
\sum_{\mathrm{j}=1}^{\mathrm{N}_{\mathrm{c}}} \mathrm{h}_{\mathrm{j}}+\sum_{\mathrm{k}=1}^{\mathrm{N}_{\mathrm{h}}} \mathrm{h}_{\mathrm{k}}=\mathrm{H}_{\mathrm{D}}
$$

The capacity limits of each unit

$$
\begin{array}{rr}
\mathrm{P}_{\mathrm{i}}^{\min } \leq \mathrm{P}_{\mathrm{i}} \leq \mathrm{P}_{\mathrm{i}}^{\max } & , \mathrm{i}=1,2, \ldots, \mathrm{Np} \\
\mathrm{P}_{\mathrm{j}}^{\min }\left(\mathrm{h}_{\mathrm{j}}\right) \leq \mathrm{P}_{\mathrm{j}}\left(\mathrm{h}_{\mathrm{j}}\right) \leq \mathrm{P}_{\mathrm{j}}^{\max }\left(\mathrm{h}_{\mathrm{j}}\right), \mathrm{j}=1,2, \ldots, \mathrm{Nc} \\
\mathrm{h}_{\mathrm{j}}^{\min }\left(\mathrm{P}_{\mathrm{j}}\right) \leq \mathrm{h}_{\mathrm{j}}\left(\mathrm{P}_{\mathrm{j}}\right) \leq \mathrm{h}_{\mathrm{j}}^{\max }\left(\mathrm{P}_{\mathrm{j}}\right), \mathrm{j}=1,2, \ldots, \mathrm{N} \\
\mathrm{h}_{\mathrm{k}}^{\min } \leq \mathrm{h}_{\mathrm{k}} \leq \mathrm{h}_{\mathrm{k}}^{\max } \quad, \mathrm{k}=1,2, \ldots, \mathrm{Nh}
\end{array}
$$

Where $f_{i}\left(P_{i}\right), f_{j}\left(P_{j}, h_{j}\right), f_{k}\left(h_{k}\right)$ are the respective fuel cost functions of power-only unit, CHP unit and heat-only unit, these cost functions are usually smooth quadratic, however, to model more realistic cost of units, the valve-point effects need to be considered. $\mathrm{P}_{\mathrm{i}}, \mathrm{P}_{\mathrm{j}}$, are the power generation of power-only and CHP units respectively; $h_{j}, h_{k}$, are heat production of CHP and heat-only units, respectively; $\mathrm{N}_{\mathrm{p}}, \mathrm{N}_{\mathrm{c}}, \mathrm{N}_{\mathrm{h}}$, are the respective numbers of the above three kinds of units. Where $P_{D}, H_{D}$ are the power and heat demand of system; $P_{L}$ is the system power transmission loss that can be calculated by B-coefficient loss formula as shown in the following:

$$
\mathrm{P}_{\mathrm{L}}=\sum_{\mathrm{i}=1}^{\mathrm{N}_{\mathrm{p}}+\mathrm{N}_{\mathrm{c}}} \sum_{\mathrm{j}=1}^{\mathrm{N}_{\mathrm{p}}+\mathrm{N}_{\mathrm{c}}} \mathrm{P}_{\mathrm{i}} \mathrm{B}_{\mathrm{ij}} \mathrm{P}_{\mathrm{j}}
$$


Where $B_{i j}$ is the loss coefficient for network branch connected between power generation units $\mathrm{i}$ and $\mathrm{j}$.

\section{Improved Harmony Search algorithm}

\section{A. Harmony Search algorithm}

Recently, Geem and al [14], proposed a new HS meta-heuristic algorithm that was inspired by musical process of searching for a perfect state of harmony. The harmony in music is analogous to the optimization solution vector, and the musician's improvisations are analogous to local and global search schemes in optimization techniques. The HS algorithm does not require initial values for the decision variables. Furthermore, instead of a gradient search, the HS algorithm uses a stochastic random search that is based on the harmony memory considering rate and the pitch adjusting rate so that derivative information is unnecessary [15].

In the HS algorithm, musical performances seek a perfect state of harmony determined by aesthetic estimation, as the optimization algorithms seek a best state (i.e. global optimum) determined by objective function value. It has been successfully applied to various optimization problems in computation and engineering fields [15].

The optimization procedure of the HS algorithm consists of Steps 1-5, as follows [16]:

Step 1: Initialize the optimization problem and algorithm parameters.

Step 2: Initialize the harmony memory $(\mathrm{HM})$.

Step 3: Improvise a new harmony from the HM.

Step 4: Update the HM.

Step 5: Repeat Steps 3 and 4 until the termination criterion has been satisfied.

The detailed explanation of these steps can be found in $[14,4]$ which are summarized in the following:

Step1. Initialize the optimization problem and HS Algorithm parameters.

First, the optimization problem is specified as follows:

Minimize $f(x)$ subject to $x_{i} \in X_{i}, i=1, \ldots, N$.

Where $f(x)$ is the objective function, $x$ is the set of each decision variable $\left(x_{i}\right) ; X_{i}$ is the set of the possible range of values for each design variable (continuous design variables), that is, $\mathrm{X}_{\mathrm{i}}$ lower $\leq$ $X_{i} \leq x_{i \text { upper }}$, where $x_{i}$ lower and $x_{i \text { upper }}$ are the lower and upper bounds for each decision variable; and $\mathrm{N}$ is the number of design variables. In this context, the HS algorithm parameters that are required to solve the optimization problem are also specified in this step. The number of solution vectors in harmony memory (HMS) that is the size of the harmony memory matrix, harmony memory considering rate (HMCR), pitch adjusting rate (PAR), and the maximum number of searches (stopping criterion) are selected in this step. Here, HMCR and PAR are parameters that are used to improve the solution vector. In this context, both are defined in Step 3.

Step2. Initialize the harmony memory (HM). The harmony memory (HM) is a memory location where all the solution vectors (sets of decision variables) are stored. In Step 2, the HM matrix, shown in "(9)", is filled with randomly generated solution vectors using a uniform distribution, where:

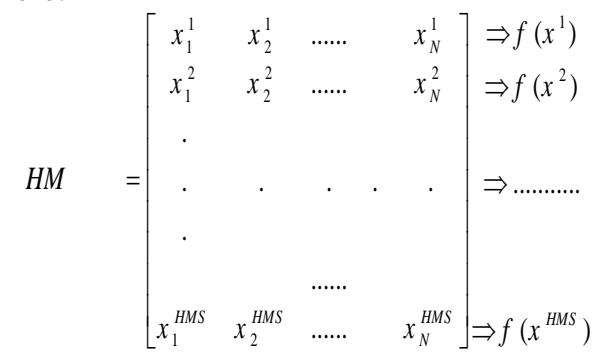


Step3. Improvise a new harmony from the HM. A new harmony vector $x^{\prime}=\left(x_{1}{ }^{\prime} \ldots x_{N}{ }^{\prime}\right)$ is generated based on three rules: (a) memory consideration, (b) pitch adjustment, and (c) random selection. Generating a new harmony is called 'improvisation'.

In the memory consideration, the value of the first decision variable $\left(x_{1}{ }^{\prime}\right)$ for the new vector is chosen from any value in the specified HM range $\left(x_{1}{ }^{\prime}, \ldots, x_{N}{ }^{H M S}\right)$. Values of the other decision variables $\left(x_{2}{ }^{\prime}, \ldots, x_{N}{ }^{H M S}\right)$ are chosen in the same manner. The HMCR, which varies between 0 and 1 , is the rate of choosing one value from the historical values stored in the HM, while (1HMCR) is the rate of randomly selecting one value from the possible range of values.

$$
x_{i}^{\prime} \leftarrow\left\{\begin{array}{c}
x_{i}^{\prime} \in\left\{x_{i}^{1} ; x_{i}^{2} ; \ldots ; x_{i}^{H M S}\right\} w . p . H M C R \\
x_{i}^{\prime} \in X_{i}, \ldots \ldots \ldots \ldots \ldots \ldots . p(1-H M C R)
\end{array}\right.
$$

After, every component obtained by the memory consideration is examined to determine whether it should be pitch-adjusted. This operation uses the PAR parameter, which is the rate of pitch adjustment as follows:

Pitch adjuseting decision for

$$
x_{i}^{\prime} \leftarrow\left\{\begin{array}{c}
\text { yes with probability PAR } \\
N O \text { with probability }(1-P A R)
\end{array}\right.
$$

The value of (1 -PAR) sets the rate of doing nothing. If the pitch adjustment decision for $x_{i}^{\prime}$ is yes, then $x_{i}^{\prime}$ is replaced as follows:

$$
x_{i}^{\prime} \leftarrow x_{i}^{\prime} \pm r . b w
$$

Where bw is an arbitrary distance bandwidth, $\mathrm{r}$ is a random number generated using uniform distribution between 0 and 1. In Step 3, HM consideration, pitch adjustment or random selection is applied to each variable of the New Harmony vector in turn.

Step4. Update the HM. If the new harmony vector, $\left(x_{1}^{\prime}, \ldots, x_{N}^{\prime}\right)$ is better than the worst harmony in the HM, judged in terms of the objective function value, the new harmony is included in the $\mathrm{HM}$ and the existing worst harmony is excluded from the HM.

Step5. Repeat Steps 3 and 4 until the termination criterion has been satisfied.

\section{B. Proposed Improved HS algorithm}

To improve the performance of the HS algorithm and eliminate the drawbacks lie with fixed values of HMCR and PAR, Mahdavi and al. [17] proposed an improved harmony search algorithm that uses variable PAR and bw in improvisation step. The IHS proposed in this work has exactly the same steps of classical HS with exception that Step 3, where the IHS dynamically updates PAR in which concepts from dispersed particle swarm optimization are adopted. The key difference between IHS and traditional HS method is in the way of adjusting PAR and bw to improve the performance of the HS algorithm and eliminate the drawbacks lies with fixed values of PAR and bw, IHS algorithm uses variables PAR and bw in improvisation step (Step 3). PAR and bw change dynamically with generation number as shown in "Figure. 2" and expressed as follow:

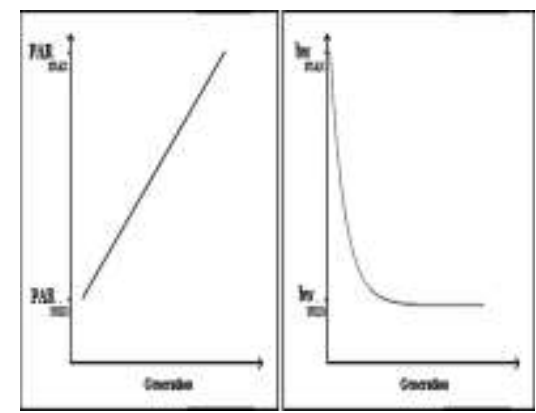

Figureure 2. Variation of PAR and bw versus generation number. 


$$
\begin{aligned}
& \qquad P A R(g n)=P A R_{\text {min }}+\frac{\left(P A R_{\max }-P A R_{\min }\right)}{N I} \times g n \\
& \text { And } \\
& \quad b w(g n)=b w_{\text {max }} \cdot \exp (c \cdot g n) \\
& \quad c=\frac{L n\left(\frac{b w_{\min }}{b w_{\max }}\right)}{N I}
\end{aligned}
$$

Where:

PAR pitch adjusting rate for each generation,

$\mathrm{PAR}_{\text {min }}$ minimum pitch adjusting rate,

$\mathrm{PAR}_{\max }$ maximum pitch adjusting rate,

NI number of solution vector generations,

gn generation number,

bw(gn) bandwidth for each generation,

bw min minimum bandwidth,

bw $w_{\max }$ maximum bandwidth.

This improvement introduces to HS algorithm makes that the algorithm tends towards the global optimum with more precision.

\section{IHS algorithm for solved CHPED problems}

Improved harmony search algorithm for solving CHPED problem is described below:

Let $X_{i}=\left[P_{1}, P_{2}, \ldots, P_{N}, P_{N+1}, P_{N+2}, \ldots, P_{C}, H_{N+1}, H_{N+2}, \ldots, H_{c}, H_{C+1}, H_{C+2}, \ldots, H_{k}\right]$ be the initial designating the $\mathrm{i}^{\text {th }}$ be the initial vector designating the $\mathrm{i}^{\text {th }}$ population to be evolved. The elements of $\mathrm{X}_{\mathrm{i}}$ are the real power outputs of conventional thermal generators and cogeneration units and heat outputs of cogeneration units and heat-only units. The elements of $\mathrm{X}_{\mathrm{i}}$ should satisfy the constraints given by "(2)" until "(7)". The IHS algorithm implemented to solve CHPED problem is stated in the following steps.

Step 1: Initialize the parameters HMS, HMCR, $\mathrm{PAR}_{\min }, \mathrm{PAR}_{\mathrm{Max}}, \mathrm{bw}_{\min }, \mathrm{bw}_{\mathrm{Max}}, \mathrm{NI}, \mathrm{gn}=1$

Step 2: Initialize harmony memory. Calculate the fitness value for all solution vectors in harmony memory.

Step 3: Improvisation process of harmony memory as mentioned in "(10)", with the parameters PAR and bw change dynamically with generation number as given by "(13)" until "(15)". Calculate the fitness value for the entire new improvised harmony/solution vectors.

Step 4: Select the best improvised solution out of entire new improvised solution vectors. Update the harmony memory if it is better than the worst harmony. Put gn $=\mathrm{gn}+1$.

Step 5: Stopping criterion if gn $<$ NI if not repeat Steps 3 and 4 until the termination criterion has been satisfied.

\section{Results and Analysis}

In this section, the results of the simulations on two test systems are presented to evaluate the effectiveness of the proposed algorithm. The data of the test systems, the simulation results and eventually the comparison of the results of the proposed algorithm with the other methods in the literature will be provided in the field of convergence speed and solution quality. The proposed HIS algorithm program has been implemented on the MATLAB7.1 on PC (Intel®, Core (TM), i5-3230M, CPU $2.60 \mathrm{GHz}, 2.60 \mathrm{GHz}$, with $4.00 \mathrm{Go}$ RAM).

The parameters of the proposed IHS algorithm for all test cases are set as follows: harmony memory size (HMS) is equal to 6, harmony memory consideration (HMCR) is equal as 0.85 and the minimum and maximum pitch adjusting rate $\left(\mathrm{PAR}_{\min }, \mathrm{PAR}_{\max }\right)$ are equals to $0.45,0.85$ respectively, the minimum and maximum bandwidth $\left(\mathrm{bw}_{\max }, \mathrm{bw}_{\max }\right)$ are equals as $0.001,1$ 
respectively. The fuel Cost is in "dollar (\$)", heat output is in "megawatt thermal (MWth)", and power output is in "megawatt (MW)" in all the test systems.

\section{A. Test system 1 .}

This is simple test system, proposed by [20], [21] includes 4 units which are one power-only unit, one heat-only unit and two cogeneration units, and it is the classical representation of simple CHPED problems and used to evaluate the algorithm in most literature of the CHPED problems. To compare the proposed algorithm with other typical algorithms, we choose the classical simple test system as the benchmark, where the power transmission loss and valvepoint effects are ignored as the same as in all other literatures.

The fuel cost formulation of the four units is given:

- Power only units: $\quad F_{1}\left(P_{1}\right)=50 P_{1} \mid \$$

- Cogeneration units:

$$
\begin{aligned}
& F_{2}\left(P_{2}, H_{2}\right)=2650+14.5 P_{2}+0.0345 P_{2}^{2}+4.2 H_{2}+0.03 H_{2}^{2}+0.031 P_{2} H_{2} \mid \$ \\
& F_{3}\left(P_{3}, H_{3}\right)=1250+36 P_{3}+0.0435 P_{3}^{2}+0.6 H_{3}+0.027 H_{3}^{2}+0.011 P_{3} H_{3} \mid \$
\end{aligned}
$$

- Heat only units: $\quad F_{4}\left(H_{4}\right)=23.4 H_{4} \mid \$$

The test system1, has 6 decision variables $\left(\mathrm{P}_{1}, \mathrm{P}_{2}, \mathrm{P}_{3}, \mathrm{H}_{2}, \mathrm{H}_{3}, \mathrm{H}_{4}\right)$, the domains of the decision variables are stated:

$\mathrm{P}_{1} \in[0,150], \mathrm{P}_{2} \in[81,274], \mathrm{P}_{3} \in[40,125.8], \mathrm{H}_{2} \in[0,180], \mathrm{H}_{3} \in[0,135.6], \mathrm{H}_{4} \in[0,2695.2]$.

The fitness function of the CHPED problem is formulated as:

$\operatorname{Min}\left\{F_{\text {total }}=F_{1}\left(P_{1}\right)+F_{2}\left(P_{2}, H_{2}\right)+F_{3}\left(P_{3}, H_{3}\right)+F_{4}\left(H_{4}\right)\right\}$

Subjected to be equality constraints: $P_{1}+P_{2}+P_{3}=P_{D}$ and $H_{2}+H_{3}+H_{4}=H_{D}$

And the inequality constraints: $0 \leq P_{1} \leq 150 \mathrm{MW}$ and $0 \leq H_{4} \leq 2695.2 \mathrm{MWth}$

The Power demands $\left(\mathrm{P}_{\mathrm{D}}\right)$ and heat demands $\left(\mathrm{H}_{\mathrm{D}}\right)$ of the test system1 are $200 \mathrm{MW}$ and $115 \mathrm{MW}$ th, respectively. These feasible operation regions are depicted in "Figure 3" and "Figure 4", for first and second CHP units of the test system 1.

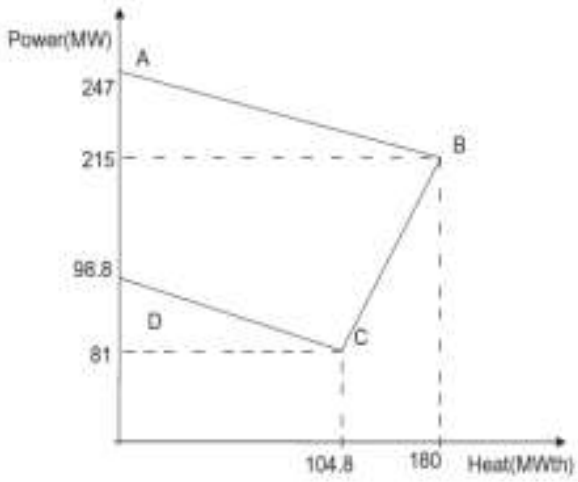

Figure 3. Feasible Operation region of the first CHP unit.

The cost convergence curve of the proposed method for the test system 1 is depicted in "Figure 5". As can be seen in this Figure, the optimization algorithm converges to the lowest optimal from 100 iterations.

The results of IHS algorithm proposed and its comparison with the classical HS algorithm [23], Genetic Algorithm (GA) [19] and Augmented Lagrange Hopfield Network (ALHN) [20] are provided in table 1 . The optimal solution of this test system 1 attained by the IHS algorithm proposed is $9179.5 \$$ for 200 iteration. According to the results, the proposed algorithm attains the optimum solution for the problem compared with the other methods. 


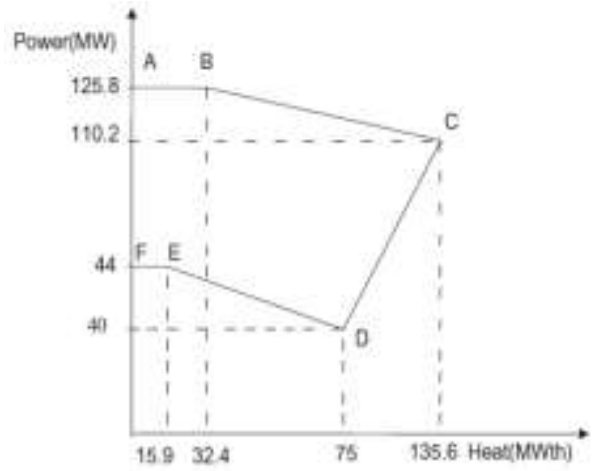

Figure 4. Feasible Operation region of the second CHP unit.

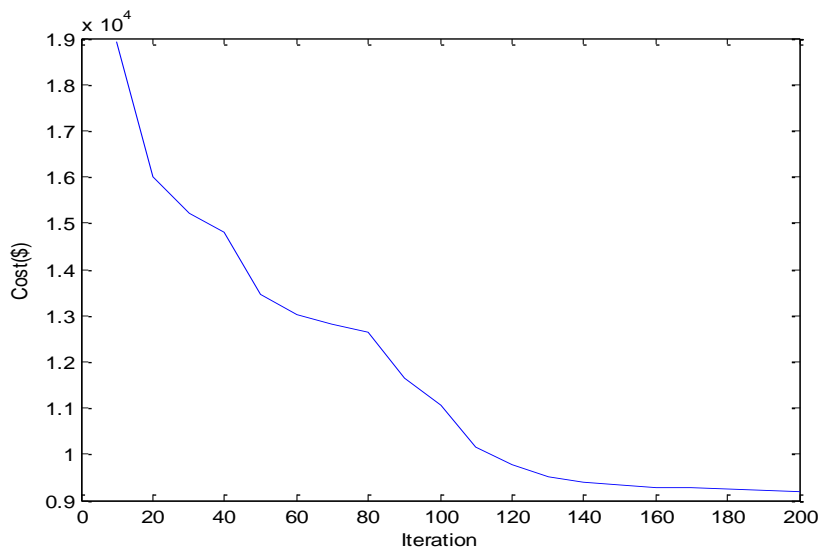

Figure 5. The Cost convergence curve for test system1.

Table 1. Comparison the best results of its algorithm with HS algorithm and other methods for test system 1

\begin{tabular}{lcccc}
\hline \hline \multicolumn{1}{c}{ Method } & IHS & HS & ALHN & GA \\
\hline P1(MW) & 5.1662 & 0.887 & 0.0 & 0.0 \\
P2(MW) & 49.00997 & 46.0268 & 159.9994 & 159.23 \\
P3(MW) & 100.1671 & 103.32 & 40.00 & 39.95 \\
H2(MWh) & 9.8193 & 1.7629 & 39.9993 & 40.77 \\
H3(MWh) & 0.3724 & 1.7952 & 75 & 75.06 \\
H4(MWh) & 4.7797 & 14.3787 & 0.0 & 0.0 \\
Cost(\$) & 9179.5 & 9230.2 & 9257.05 & 9267.2 \\
\hline
\end{tabular}

B. Test system 2

This simple test system case proposed by [8], [13] consists of 4 power only-units, two cogeneration units and one heat-only unit, and it is a classical representation of sophisticated CHPED problems and used to evaluate the algorithms in most literature. In this test system, the valve-point effects of the power unit and power net transmission losses in the CHPED problem are considered as the same as in all the other referred literatures [5].

The fuel cost formulation of the four power-only units, two cogeneration units, and one heat unit are given:

Power only units: 


$$
\begin{aligned}
& F_{1}\left(P_{1}\right) 25+2 P_{1}+0.008 P_{1}^{2}+\left|100 \sin \left\{0.042\left(P_{1}^{\min }-P_{1}\right)\right\}\right| \mid \$ \quad 10 \leq P_{1} \leq 75 \mathrm{MW} \\
& F_{2}\left(P_{2}\right)=60+1.8 P_{2}+0.003 P_{2}^{2}+\left|140 \sin \left\{0.04\left(P_{2}^{\min }-P_{2}\right)\right\}\right| \$ 20 \leq P_{2} \leq 125 \mathrm{MW} \\
& F_{3}\left(P_{3}\right)=100+2.1 P_{3}+0.0012 P_{3}^{2}+\left|160 \sin \left\{0.038\left(P_{3}^{\min }-P_{3}\right)\right\}\right| \$ \quad 30 \leq P_{3} \leq 175 \mathrm{MW} \\
& F_{4}\left(P_{4}\right)=120+2 P_{4}+0.001 P_{4}^{2}+\left|180 \sin \left\{0.037\left(P_{4}^{\min }-P_{4}\right)\right\}\right| \$ \quad 40 \leq P_{4} \leq 250 \mathrm{MW}
\end{aligned}
$$

- Cogeneration units:

$$
\begin{aligned}
& F_{5}\left(P_{5}, H_{5}\right)=2650+14.5 P_{5}+0.0345 P_{5}^{2}+4.2 H_{5}+0.03 H_{5}^{2}+0.031 P_{5} H_{5} \mid \$ \\
& F_{6}\left(P_{6}, H_{6}\right)=1250+36 P_{6}+0.0435 P_{6}^{2}+0.6 H_{6}+0.027 H_{6}^{2}+0.11 P_{6} H_{6} \mid \$
\end{aligned}
$$

- Heat only units:

$$
F_{7}\left(H_{7}\right)=950+2.0109 H_{7}+0.038 H_{7}^{2} \mid \$ \quad 0 \leq H_{7} \leq 2695.2 \text { MWth }
$$

The test system2, has 9 decision variables $\left(\mathrm{P}_{1}, \mathrm{P}_{2}, \mathrm{P}_{3}, \mathrm{P}_{4}, \mathrm{P}_{5}, \mathrm{P}_{6}, \mathrm{H}_{5}, \mathrm{H}_{6}, \mathrm{H}_{7}\right)$, the domains of decision variables are stated:

$\mathrm{P}_{1} \in[10,75], \mathrm{P}_{2} \in[20,125], \mathrm{P}_{3} \in[30,175], \mathrm{P}_{4} \in[40,250], \mathrm{P}_{5} \in[81,247], \mathrm{H}_{5} \in[0,180], \mathrm{P}_{6} \in[40,125.8]$, $\mathrm{H}_{6} \in[0,135.6], \mathrm{H}_{7} \in[0,60]$.

The fitness function of the CHPED problem is formulated as:

$$
\operatorname{Min}\left\{F=F_{1}\left(\mathrm{P}_{1}\right)+\mathrm{F}_{2}\left(\mathrm{P}_{2}\right)+\mathrm{F}_{3}\left(\mathrm{P}_{3}\right)+\mathrm{F}_{4}\left(\mathrm{P}_{4}\right)+\mathrm{F}_{5}\left(\mathrm{P}_{5}, \mathrm{H}_{5}\right)+\mathrm{F}_{6}\left(\mathrm{P}_{6}, \mathrm{H}_{6}\right)+\mathrm{F}_{7}\left(\mathrm{H}_{7}\right)\right\}
$$

Subjected to be equality constraints:

$$
\mathrm{P}_{1}+\mathrm{P}_{2}+\mathrm{P}_{3}+\mathrm{P}_{4}=\mathrm{P}_{\mathrm{d}}+\mathrm{P}_{\mathrm{L}} \mathrm{MW} \quad \mathrm{H}_{5}+\mathrm{H}_{6}+\mathrm{H}_{7}=\mathrm{H}_{\mathrm{d}} \quad \text { MWth }
$$

Where:

$$
\begin{aligned}
& \mathrm{P}_{\mathrm{L}}=\sum_{\mathrm{i}=1}^{\beta} \sum_{\mathrm{j}=1}^{\beta} \mathrm{P}_{\mathrm{i}} \mathrm{B}_{\mathrm{ij}} \mathrm{P}_{\mathrm{j}} \\
& \text { For } \quad B=\left[\begin{array}{rrrrrr}
49 & 14 & 15 & 15 & 20 & 25 \\
14 & 45 & 16 & 20 & 18 & 19 \\
15 & 16 & 39 & 10 & 12 & 15 \\
15 & 20 & 10 & 40 & 14 & 11 \\
20 & 18 & 12 & 14 & 35 & 17 \\
25 & 19 & 15 & 11 & 17 & 39
\end{array}\right] * 10^{-7}
\end{aligned}
$$

The power demands $\left(\mathrm{P}_{\mathrm{D}}\right)$ and heat demands $\left(\mathrm{H}_{\mathrm{D}}\right)$ of the test system1 are $600 \mathrm{MW}$ and 150MWth, respectively.

And the inequality constraints:

$$
\begin{gathered}
\mathrm{g}_{1}=1.781914894 \mathrm{H}_{5}-\mathrm{P}_{5}-105.7446809 \leq 0 \\
\mathrm{~g}_{2}=0.1777777784 \mathrm{H}_{5}+\mathrm{P}_{5}-247.0 \leq 0 \\
\mathrm{~g}_{3}=-0.169847328 \mathrm{H}_{5}-\mathrm{P}_{5}+98.8 \leq 0 \\
\mathrm{~g}_{4}=1.158415842 \mathrm{H}_{6}-\mathrm{P}_{6}-46.88118818 \leq 0 \\
\mathrm{~g}_{5}=0.151162791 \mathrm{H}_{6}+\mathrm{P}_{6}-130.6976744 \leq 0 \\
\mathrm{~g}_{6}=-0.06768189 \mathrm{H}_{6}-\mathrm{P}_{6}+45.07614213 \leq 0
\end{gathered}
$$

The convergence curve of the proposed method for the test system2 is depicted in "Figure 6". As can be seen in this Figure, the optimization algorithm converges to the lowest optimal from 300 iterations.

The results of IHS algorithm proposed and its comparison with the classical HS algorithm [24], Artificial bee colony optimization (ABC) [8] and Bee colony optimization (BCO) [13] are provided in table 2 . The optimal solution of this test system 2 attained by the IHS algorithm proposed is $9303.3 \$$ for 800 iteration. According to the results, the proposed algorithm attains the optimum solution for the problem compared with the other methods.

Also from table 2, it can be observed that the CPU time of IHS algorithm is equal as 2.42 second, and the power net transmission loss is equal as $3.020 \mathrm{MW}$. 
Therefore, the results of the fuel cost, the power net transmission and the CPU time of HIS proposed are much less than that of the classical HS and other methods.

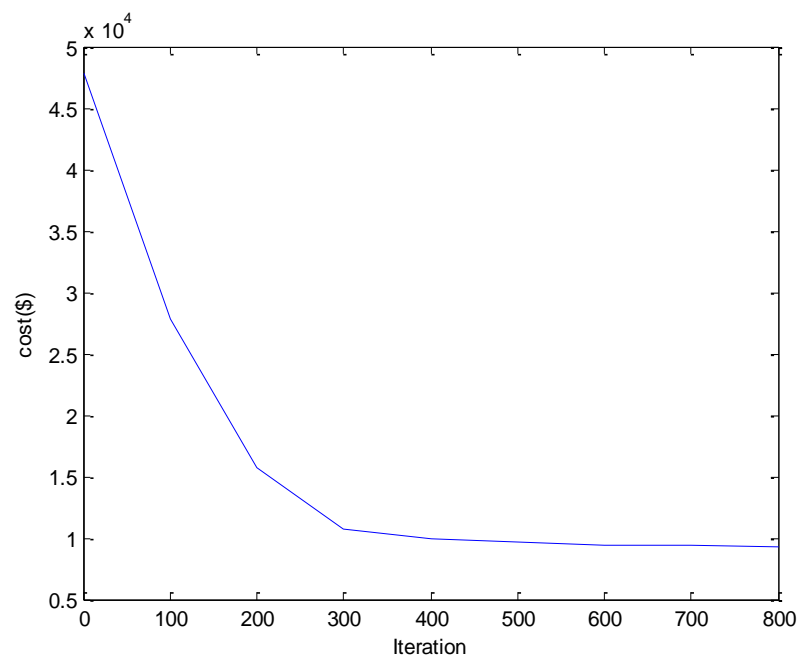

Figure 6. Cost convergence curve for test system2

Table 2. Comparison the best results of IHS algorithm with HS algorithm and other methods for test system2

\begin{tabular}{lcccc}
\hline \hline Method & IHS & HS & ABC & BCO \\
\hline P $_{\mathbf{1}}$ (MW) & 13.9698 & 13.6214 & 58.7117 & 43.9457 \\
$\mathbf{P}_{\mathbf{2}}$ (MW) & 20.2684 & 21.5668 & 98.5398 & 98.5888 \\
$\mathbf{P}_{\mathbf{3}}$ (MW) & 37.3182 & 33.7532 & 112.6735 & 112.930 \\
$\mathbf{P}_{\mathbf{4}}$ (MW) & 41.3764 & 41.2658 & 209.8158 & 209.779 \\
$\mathbf{P}_{\mathbf{5}}$ (MW) & 96.7436 & 95.5091 & 81.00 & 98.8000 \\
$\mathbf{P}_{\mathbf{6}}$ (MW) & 40.9035 & 42.1660 & 40.00 & 4.000 \\
H$_{\mathbf{5}}$ (MWth) & 16.1310 & 19.9656 & 23.1014 & 12.0974 \\
H$_{\mathbf{6}}$ (MWth) & 75.0681 & 75.8909 & 72.2437 & 78.0236 \\
H$_{\mathbf{7}}$ (MWth) & 0.89750 & 0.2033 & 54.6549 & 59.879 \\
$\mathbf{P}_{\mathbf{L}}$ (MW) & 3.020 & 3.7854 & 2.88 & 8.0384 \\
Cost $\mathbf{( \$ )}$ & 9303.3 & 9367.7 & 10314 & 10317 \\
Time (s) & 2.43 & 2.53 & 4.981 & 5.1563 \\
\hline \hline
\end{tabular}

From results simulation of test system1, and test system2, the Improved Harmony Search algorithm (IHS) proposed obtains global optimal fuel cost than the classical HS algorithm and other methods. The reason for this phenomenon is that the PAR and bw parameters are dynamically adjusted, where as in classical HS algorithm the PAR and bw parameters are fixed. Therefore, the conclusion can be drawn that IHS algorithm is an effective way to solving the CHPED problem.

\section{Conclusions}

In this paper, improved harmony search algorithm is proposed to solve the combined heat and power economic dispatch (CHPED) problem was presented. We suggested solving CHPED using the proposed IHS algorithm for two standard test systems were presented to demonstrate 
the effectiveness and robustness of this algorithm. In all cases, the solutions obtained using IHS algorithm were better than those obtained by a simple HS algorithm and other methods.

\section{References}

[1]. A. Najafi, H. Falaghi, M. Ramezani, "Combined Heat and Power Economic Dispatch Using Improved Differential Evolution Algorithm”, International Journal of Advanced Research in Computer Science and Software Engineering. Vol.2, August 2012.

[2]. H. A. Shayanfar, A. Ghasmi, N. Amjady, "PSO-IIW for combined heat and Power economic dispatch", International Journal technical and physical problems of engineering. Vol.4, pp. 51-55, June 2012.

[3]. BK. Panigrahi, VR. Pandi, S. Das, "Adaptive particle swarm optimization approach for static and dynamic economic load dispatch". Energy Convers Manage. Vol.49, pp. 407$15,2008$.

[4]. A. Vasebi, M. Fesanghary, S.M.T. Bathaee, "Combined Heat and Power Economic Dispatch by Harmony Search Algorithm “, International Journal of Electrical Power Energy Systems, Vol. 29, pp. 713-719, 2007.

[5]. M. Basu "A simulated annealing-based goal-attainment method for economic emission load dispatch of fixed head hydrothermal power systems". Int J Electr Power Energy Syst: 2005. Vol. 27, pp.147-53.

[6]. Bin Shi, Lie-Xiang Yan, Wei Wu, "Multi-objective optimization for combined heat and power economic dispatch with power transmission loss and emission reduction, "2013.

[7]. Y.H Song, Q. Y. Xuan, "Combined Heat and Power Economic Dispatch using Genetic Algorithm based Penalty function method". Electrical Machines \& Power Systems, vol.26, pp. 363-372, 1998.

[8]. R., M.R. Mohan, "Artificial Bee Colony Optimization for the Combined Heat and Power Economic Dispatch problem". ARPN Journal of Engineering and applied sciences. vol. 7, 2012.

[9]. H.V. Larsen, H. Palsson, H.F. Ravn, "Probabilistic Production Simulation Including Combined Heat andPower Plants", Electric Power Systems Research, Vol. 48, pp. 45-56, 1998.

[10]. Y.H. Song, C.S. Chou, T.J. Stonham, "Combined Heat and Power Dispatch by Improved Ant Colony Search Algorithm”, Electric Power Systems Research, Vol. 52, pp. 115-121, 1999.

[11]. C.T. Su, C.L. Chiang, "An Incorporated Algorithm for Combined Heat and Power Economic Dispatch”, Electric Power Systems Research, Vol. 69, pp.187-195, 2004.

[12]. T. Guo, M.I. Henwood, M. Van Ooijen, "An Algorithm for combined Heat and Power Dispatch”, IEEE Transactions on Power Systems, Vol. 11, pp. 1778-1784, 1996.

[13]. Basu, "Bee colony optimization for combined heat and power economic dispatch" Expert system with applications, Vol.38, pp. 13527-13531, 2011

[14]. Z, W. Geem, J, H. Kim., G, V. Goganathan, “A New Heuristic Optimization Algorithm HarmonySearch". SIMULATION, Vol.76, pp. 60-68, 2001.

[15]. Z, W. Geem, "Improved Harmony Search from Ensemble of Music Players", International Conference on Knowledge-Based Intelligent Information and Engineering Systems, Vol.4253, pp. 86-93, 2006.

[16]. A, L koridak, M.Rahli, D.Lefebvre, F-Z. Benayed, "Optimisation d'un Dispatching Economique et En vironnemental d'Energie Electrique par l'Algorithme HarmonySearch",

[17]. M. Mahdavi, M. Fesanghary, E. Damangir, "An improved harmony search algorithm for solving optimization problems", Applied Mathematics and Computation, vol. 188, pp. 1567-1579, 2007. 
[18]. KS Lee, KS. Geem, A, "new meta-heuristic algorithm for continuous engineering optimization: harmony search theory and practice", Comput Methods Appl Mech Eng 2005, Vol.194, pp.36-38.

[19]. Y.H. Song, Q.Y. Xuan, "Combined Heat and Power Economic Dispatchusing Genetic Algorithm based Penalty function method". Electrical Machines \& Power Systems, Vol.26, pp. 363-372, 1998.

[20]. N. Dieu, Vo, W. Ongsakul, "Combined Heat and Power Economic Dispach by Augmented Lagrange Hopfield Network". 16th PSCC, Glasgow, Scotland, 2008.

[21]. VN. Dieu, W. Ongsakul, "Augmented Lagrange Hopfield network for economic load dispatch with combined heat and power". Electr Power "Comp Syst, vol. 37, pp. 1289304, 2009.

[22]. D. Karaboga and B. Basturk, "The performance of artificial bee colony (ABC) algorithm. Applied soft computing”. Vol.8, pp 687-697, 2008.

[23]. F. Z. Benayed, L. Abdelhakem-Koridak, M. Rahli, "Harmony Search Algorithm Optimization for the combined heat and power economic dispatch". Article conference CESA2015.

[24]. F. Z. Benayed, L. Abdelhakem-Koridak, M. Rahli. "Dispatching économique de la production combinée d'électricité et la chaleur par l'algorithme harmony search", article conférence ICMS2014.
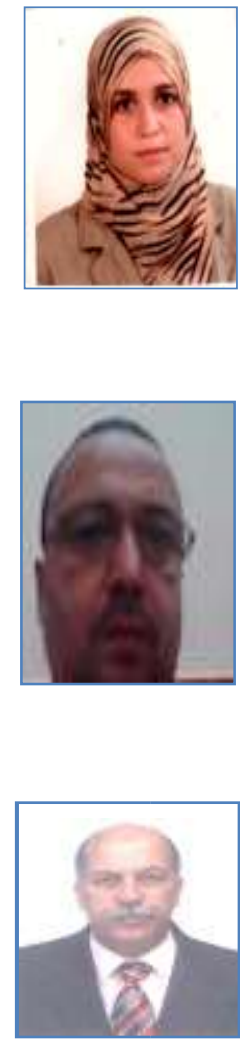

Fatima Zohra BENAYED was born on June 21, 1985 in Oran, Algeria. She is a $\mathrm{PhD}$ student in the Electrical Engineering Faculty at the University of Science and Technology of Oran Mohamed Boudiaf (USTO"MB") and M.S. degree in 2012 from She received her B.S. degree in 2003 She is currently an engineer in the laboratory of the University Oran1. His research interests include operations, planning and economics of electrical energy systems, as well as theory of optimization and its applications. benayedf@yahoo.fr

Lahouari ABDELHAKEM-KORIDAK was born on March 12, 1966 in Oran, Algeria. Director of laboratory optimization of electrical Networks, in the Electrical Engineering Faculty at the University of Science and Technology of Oran Mohamed Boudiaf, USTO”MB”; BP 1505, Oran El M'naouar, Oran, Algeria. hkoridak@yahoo.fr

Mostefa RAHLI was born in 1949 in Mocta-Douz, Mascara, Algeria. Professor in the Electrical Engineering Faculty at the University of Science and Technology of Oran Mohamed Boudiaf, USTO"MB”; BP 1505, Oran El M'naouar, Oran, Algeria.

$\underline{\text { rahlim@yahoo.fr }}$ 